\title{
A Cross-Cultural Comparison of Three Risk Tolerance Measures: Turkey and the United States Case
}

\author{
Jorge Ruiz-Menjivar ${ }^{\mathrm{a}}$, Amanda Blanco ${ }^{\mathrm{b}}$, Zeynep Çopur ${ }^{\mathrm{c}}$, Michael S. Gutter ${ }^{\mathrm{b}}$, Martie Gillen $^{\mathrm{b}}$ \\ ${ }^{a}$ University of Georgia, Department of Financial Planning, Housing, and Consumer Economics, Athens, Georgia, United States \\ ${ }^{b}$ University of Florida, Department of Family, Youth and Community Sciences, Gainesville, Florida, United States \\ ${ }^{c}$ Hacettepe University, Department of Family and Consumer Sciences, Ankara, Turkey
}

\begin{abstract}
An individual's attitude toward financial risk tolerance (FRT) is an important preference that influences financial decisionmaking under uncertainty. FRT involves inter-temporal resource allocation. Accurate and reliable measures of FRT are essential for professionals advising consumers as well as researchers who are trying to predict, and understand consumer behavior. This study explores cross-cultural risk tolerance by comparing random samples from Turkey, and the United States. Similar and distinctive attitudes and patterns regarding FRT are identified. Three subjective measures of FRT are employed in this study: Grable and Lytton (1999), Hanna, Gutter and Fan's (2001) improved version of Barsky, Juster, Kimball and Shapiro (1997), and the Survey of Consumer Finance's item on risk tolerance. Data was collected via an online survey that used the above-mentioned FRT measures. There were two versions: the original American English version, and a culturally translated Turkish version. To explore the correlation of FRT among measures, we use bivariate analysis by individually employing Pearson Chi-square test of independence, and cross tabulations analysis to each sample. In addition, by pooling both samples, we conduct cumulative logistic regression. We delineate FRT differences and consistencies between countries across subjective financial risk tolerance measures.
\end{abstract}

Key Words: Financial risk tolerance, Cross-cultural comparison, Risk tolerance measures

\section{(C) 2013 Published by SSBFNET}

\section{Introduction}

In practice, financial planners, coaches and mentors seek to understand and measure a consumer's risk tolerance in order to accurately advise them on investment and insurance decisions. In research, measures of financial risk tolerance (FRT) are used in various fields of study, from financial planning to health. Thus, accurate measures of FRT are vital to consumers, and those who serve consumers. There is a significant amount of research on how to improve the existing measures of risk tolerance. The legitimacy of findings from studies that employ the use of FRT measures is contingent upon the validity of the measure used. However, there is a paucity of research on the interreliability of the instruments. The main purpose of this study is to explore if there is consistency between measures of risk tolerance. This study will cross-culturally compare three measures of risk tolerance: Grable \& Lytton (1999), Hanna, Gutter and Fan's (2001) improved version of Barsky, Juster, Kimball and Shapiro (1997), and the Survey of Consumer Finances question on risk tolerance. In addition, this research aims to analyze financial risk tolerance (individual's attitude towards risk) from a cross-cultural perspective, comparing American and Turkish students. By using a comparative approach, we can both identify similarities and examine distinctive attitudes and patterns in each population.

\footnotetext{
${ }^{\mathrm{a}}$ Corresponding author Jorge Ruiz-Menjivar, Tel.: +1 706-542-4655.
} 
Ruiz-Menjivar et al. International Journal of Research in Business and Social Sciences Vol. 3, No.1, 2014. ISSN: $2147-4478$

\section{Literature Review}

According to Hanna, Gutter and Fan (2001) there is a minimum of four different methods to measure risk tolerance. The present study compares three of the four types of indices used to measure risk tolerance: investment choice measures, mixed measures and hypothetical questions. The fourth type of risk tolerance measure is an objective measure and evaluates actual behavior.

The FRT indices employed in this study include: the Survey of Consumer Finances item or SCF measure, Grable and Lytton's (1999) measure and Hanna, Gutter and Fan's (2001) improved measure of Barsky, Juster, Kimball and Shapiro (1997). Measures of risk tolerance can be categorized as theoretical and nontheatrical measures.

The SCF measure is the only measure used in this study that is not explicitly based on theory. The SCF item asks how much risk a consumer is willing to take. The SCF measure is favored by many researchers because it a concise measurement of risk tolerance that will not considerably increase the length of a survey.

Grable and Lytton's (1999) is a mixed measure of risk tolerance based on eight dimension of risk: "1) guaranteed versus probable gambles, 2) general risk choice, 3) choice between sure loss and sure gain, 4) risk as related to experience and knowledge, 5) risk as a level of comfort, 6) speculative risk, 7) prospect theory, and 8) investment risk" (p.174). It is commonly used by researchers located both in and outside the United States commonly use this measure.

Hanna, Gutter and Fan's (2001) improved version of Barsky, Juster, Kimball and Shapiro (1997) is founded from economic theory. It examines risk tolerance as loss in retirement income. Barsky, Juster, Kimball and Shapiro (1997) original instrument measured risk tolerance as loss in employment income and was created to for inclusion in the Health and Retirement Study (HRS).

\section{Reliability and Validity of Risk Tolerance Measures}

Reliability is often cited as a prerequisite for measurement validly. Reliability is concerned with random error and validity is concerned with systematic error in a measurement (Adcock \& Collier, 2001). Reliability signifies "how free and item or scale is from measurement error" (Grable \& Schumm, 2007, p. 3). In other words, you can test a measure under similar conditions and collect comparable results.

Grable and Schumm (2007) examined the reliability of the SCF measure of risk tolerance and determined that the item's internal consistency, as measured by the Cronbach's alpha, to be comparatively low at an estimated .59 . Grable and Lytton (1999) reported a Cronbach's alpha of 0.7507 for their measurement of risk tolerance. A measurement of consistency was not reported by Hanna, Gutter and Fan (2001) or Barsky, Juster, Kimball and Shapiro (1997).

In general, all three measures are widely accepted as reliable measures of risk tolerance, but all three do not satisfy the four primary types of validity: face, content, construct and criterion (Grable \& Lytton, 2001). In terms of validity, scholars have examined validity in the SCF and Grable and Lytton (2001) more than Hanna, Gutter and Fan's version of Barsky, Juster, Kimball and Shapiro (1997) FRT measure. The first and mildest test of validity is face validity. It is an informal test of accuracy determined by laypersons (Litwin, 1995 as cited by Grable \& Lytton, 2001). Based on the wide usage of these measures of risk tolerance it can be inferred that all three measures have face validity.

Content validity is fulfilled when the measure passes a "formal review by individuals who are experts" in the content being measured (Litwin, 1995, p. 82 as cited by Grable \& Lytton, 2001). This review determines if the items capture the scope of the topic being examined. Concise measures of phenomenon can exist but the brevity of the SCF measure and lack of theoretical basis indicates that it does not have content validity. It can be argued that other two measures have content validity since they are theoretically based and have been reviewed and revised by respected scholars. 
There are inconsistencies in what constitutes as construct validity. In general this type of validity requires that indicators, represented by items, be interrelated in a way that is consistent with the theory employed to create the measurement (Adcock and Collier, 2001). Using this definition, the SCF measure does not satisfy the premise of theoretical basis and therefore cannot have construct validity. The theoretically based measures employed in this study are accepted as having contract validity but more research is needed to support this argument.

Finally, a measure is considered to have criterion validity and/or concurrent validity when it parallels other measures examining the same phenomenon (Grable \& Lytton, 2001). By comparing the three measures of FRT, this research hopes to provide support for or against the concurrent validly of measures.

Measures can have all four types of validity in one country but it cannot be assumed that validity will transfer to populations outside that country. Many international studies have already used American measures of FRT. The SCF measure and the Grable and Lytton (1999) measure have been the most cited. Anbar and Eker (2010) employed Grable and Lytton's (1999) measure of FRT to explore the relationship between FRT levels and demographic variables in college students in Turkey. In an exploratory study on saving behavior, Copur, Gutter and Erkal (2010) measured risk tolerance, in Turkish households, using the SCF question. Fan and Xiao (2006) used the categories from the SCF measure to explore cross-cultural differences in FRT.

\section{Methodology and Data}

\subsection{Data and Sample}

Data was collected via an online survey that used three financial risk tolerance measures: the Survey of Consumer Finance's item on risk tolerance Grable and Lytton (1999), Hanna, Gutter and Fan's (2001) improved version of Barsky, Juster, Kimball and Shapiro (1997). A native speaker, who is also fluent in English, translated the survey into Turkish. All demographic variables were kept from the original study on the American sample (see Blanco, Gutter, Ruiz-Menjivar, Spangler \& Wynn, 2012) except race and ethnicity. This question was removed for the Turkish version of the survey since the Turkish group is a largely homogeneous population. For comparability purposes, the variables of race/ethnicity were completely removed from the United States Sample when performing the statistical analysis.

Sample populations from both countries were registered undergraduate students from relatively large, comprehensive public universities recruited by employing a random sample of official school email addresses provided by the respective registrar's office of each participating university. For the American group, registrar's office provided the email addresses of 2,000 students. The response rate was $10 \%$ (200 responses), including attrition. However, only 173 were valid responders - participants being 18 or over and completing the survey. In the case of the Turkish group, the registrar sent the link to the survey to more than 10,000 students. The response rate was around $23 \%$ (2261 responses), including incomplete surveys; thus, the number of total valid responses was 1,281 for the Turkish sample.

For the United States group, there was a total of 173 responses; nonetheless, we invalidated 2 responses; this was because either or both a) the student identified himself/herself as a graduate student, and for this study only undergraduate students are meant to be considered; b) the student disclosed his/her gender as "prefer not to say". Initially, students who marked this category were considered. However, the subsample of students in this group was too small for statistical purposes; thus, was not practical.

In the case of Turkey, we drew a random sample of 200 valid responses from the total survey sample. By adjusting the Turkish sample size, the model would have comparable research power (van Belle, 2011) for each sample. From the 200 random samples, 7 responses were omitted due to the same statistical refinement parameters used for the United States sample. 
Ruiz-Menjivar et al. International Journal of Research in Business and Social Sciences Vol. 3, No.1, 2014. ISSN: $2147-4478$

The final sample is comprised of 171 responses for the United States and 193 responses for Turkey. We used the total of 364 responses when pooling both countries' responses for the cumulative logistic regression analysis.

\subsection{Procedure}

The online survey instrument was created using all the items from the above mentioned risk tolerance measures. Participants were requested to complete these measures along with a set of demographic questions. The version of the survey used to collect data in Turkey was trans-created. Adjustments for language along with cultural and contextual adjustments were also made for fair comparison.

\subsection{Measurement of Variables}

The responses obtained from the three measures were scored using each author's particular coding specifications. For the particular and comparative purpose of this study, we categorized the responses in four different dimensions: high risk, above average risk, moderate risk and low risk. These groups parallel the classification adopted by the Survey of Consumer Finance's risk tolerance measure. In order to parallel the categories found in the other two measures, Grable and Lytton (1999) and Barsky et al. (1997), the categories of risk tolerance were combined within each measure.

One important note about the categorization of levels of risk tolerance is that the "no financial risk" category from the Survey of Consumer Finances was not adopted and instead we used "low risk" as a dimension. We support this decision using the notion that all decisions, in practice, are made under an environment of at least one uncertain factor. Exhibit 1 graphically represents the comparison of risk tolerance dimensions.

Exhibit 1. Comparison of Risk Tolerance Categories

\begin{tabular}{|c|c|c|c|c|}
\cline { 3 - 5 } \multicolumn{1}{c|}{} & This study & Non-theoretical & \multicolumn{2}{c|}{ Theorethical } \\
\hline Measure & High Risk & Substantial & High & Extremely High \\
\cline { 2 - 5 } & $\begin{array}{c}\text { Above Average } \\
\text { Risk }\end{array}$ & Above Average & Above Average & Very high \\
\cline { 2 - 5 } $\begin{array}{c}\text { Categories of Risk } \\
\text { Tolerance }\end{array}$ & Moderate Risk & Average & Average & $\begin{array}{c}\text { Moderately high/ } \\
\text { Moderate }\end{array}$ \\
\cline { 2 - 5 } & Low Risk & No Financial Risk & $\begin{array}{c}\text { Below Average/ } \\
\text { Low }\end{array}$ & $\begin{array}{c}\text { Low } \\
\text { Very Low/ } \\
\text { Extremely Low }\end{array}$ \\
\hline
\end{tabular}

\subsection{Dependent Variables}

The three dependent variables utilized for the inferential statistics in this study are a) consistent in all three measures, $b$ ) consistent in theoretical measures and c) consistent in non-theoretical measures. These variables come from the four dimensions created for our purpose: high risk, above average risk, moderate risk and low risk.

The consistency in all three measures was defined by assessing whether the response of a participant on risk the three tolerance measures (Grable and Lytton (1999), Barsky et al. (1997) and the SCF) was consistent in each of the created dimensions in this study. The next two independent variables are derived from the consistency in 2 measures. For comparative purposes, we divide the responses consistent in 2 measures in theoretical and nontheoretical. The theoretical perspective includes the comparison between Barsky et al. (1997) against Grable and Lytton (1999). On the other hand, the non-theoretical perspective encompasses the comparison of both a) Barsky et 
Ruiz-Menjivar et al. International Journal of Research in Business and Social Sciences Vol. 3, No.1, 2014. ISSN: $2147-4478$

al. (1997) and the Survey of Consumer Finances question on risk tolerance (SCF) and b) Grable and Lytton (1999) and the SCF. Exhibit 2 illustrates the scheme of our dependent variables.

Exhibit 2. Dependent Variables

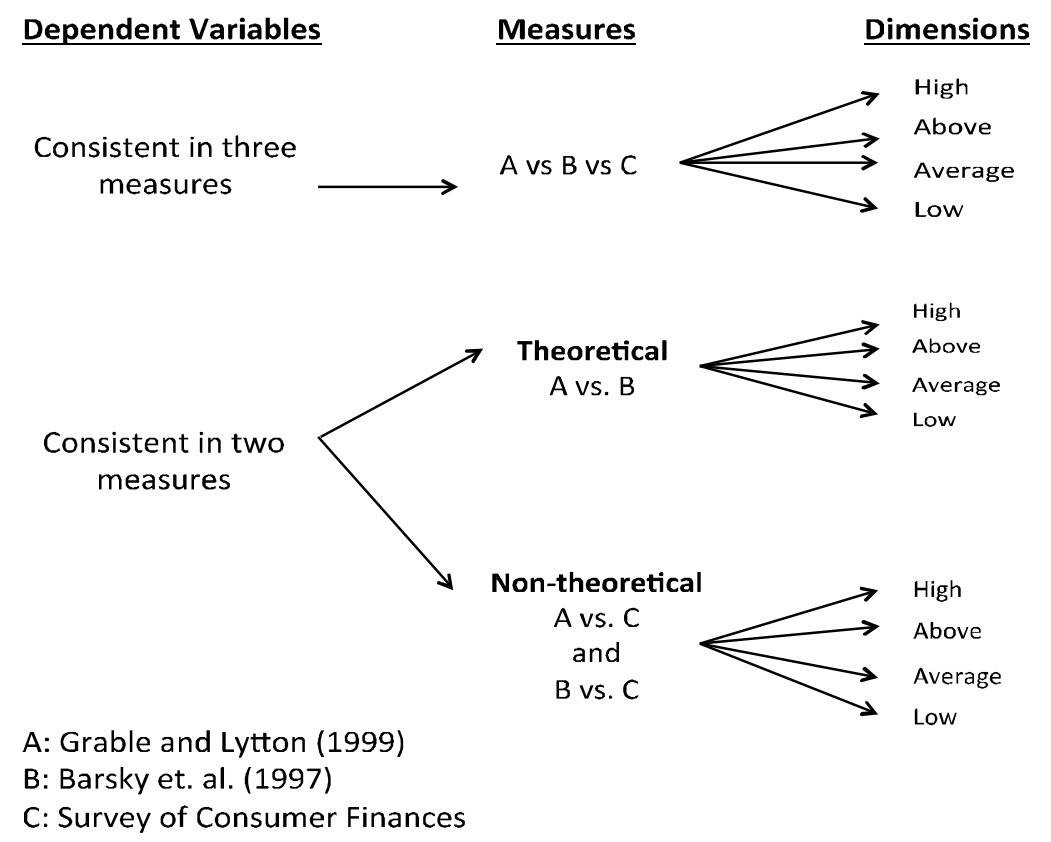

\subsection{Independent variables}

In this cross-cultural study, the primary independent variable was the country of origin. This variable was coded as "1" if the observation was from the United States and as " 0 " if the response was from Turkey. The other variables included in the regression analysis were native language, gender and participation in financial services. For the variable of gender, only those respondents who either identified as male or female were included in the study. In our survey, we did have an option for respondents to select "prefer not say," as the use of this subcategory was not practical for statistical analyses. The last variable, participation in financial services was equal to the summation of several financial components/vehicles: savings account or checking account, certificated of deposit or money market, IRA, 401k, 403 (b) or other employer plan, credit card, installment loan, mortgage (including $2^{\text {nd }}$ mortgage), home equity loan and reverse mortgage.

\subsection{Analyses}

As part of the descriptive statistics and preliminary analyses, we calculated the sample profile for each group, Turkish and American. Then, we conducted bivariate analyses to compare both groups. The Pearson's chi-square was computed for the independent variables used in this study. We calculated chi-square for the respective original financial risk tolerance categories within each measure. We were able to assess how well scores on one measure predict scores on the other two. Also, Pearson's chi-square was used with the consistency variables by country: consistency across all three measures, consistency in theoretical measures and consistency in non-theoretical measure. Finally, using both samples merged, we ran cumulative logistic regression. Odds ratios were calculated to estimate the likelihood of being consistent between theoretical measures, non-theoretical measures, and among all three measures. 
Ruiz-Menjivar et al. International Journal of Research in Business and Social Sciences Vol. 3, No.1, 2014. ISSN: $2147-4478$

\section{Findings and Discussion}

\subsection{Bivariate Analysis}

This section presents the bivariate results of each dependent and independent variables along with its respective sample profile. Tables 1-3 display the frequency and the results of the bivariate analysis for each country, the United States and Turkey.

\subsubsection{Independent Variables}

First, we conducted a bivariate analysis to account for differences in the independent variables by country. Table 1 shows the frequencies and bivariate analysis (Pearson's Chi-square) for the independent variables used in this study. The only independent variable that significantly differed between the United States and Turkey was the participation in financial services $\left(\chi^{2}=67.731, p<0.001\right)$. Almost all $(98.83 \%)$ of the respondents from the United States indicated that they participated in at least one mainstream financial service compared to $34.34 \%$ from Turkey. Of participants from the United States, $1.17 \%$ specified that they did not participate in any financial service compared to $35.23 \%$ of the Turkish sample.

Table 1. Frequency and Bivariate Analysis Results for Independent Variables

\begin{tabular}{|c|c|c|c|}
\hline & United States & Turkey & \\
\hline & Frequency $(\%)$ & Frequency $(\%)$ & Chi-square \\
\hline \multicolumn{4}{|l|}{ Variables } \\
\hline \multicolumn{4}{|l|}{ Gender (male) } \\
\hline Male & $46(26.90)$ & $66(34.20)$ & 2.2659 \\
\hline Female & $125(73.10)$ & $127(65.80)$ & \\
\hline Language & & & 3.8085 \\
\hline Native & $154(90.06)$ & $184(95.34)$ & \\
\hline Non-native & $17(9.94)$ & $9(4.66)$ & \\
\hline Participation in Financial Services & & & $67.7314^{*}$ \\
\hline $\begin{array}{l}\text { Participate in at least } 1 \text { mainstream financial } \\
\text { service }\end{array}$ & $169(98.83)$ & $125(34.34)$ & \\
\hline Participate in 0 mainstream financial service & $2(1.17)$ & $68(35.23)$ & \\
\hline
\end{tabular}

Notes: English for The Unites States Sample; and Turkish for the Turkey sample

${ }^{*} p<0.001$ 
Ruiz-Menjivar et al. /International Journal of Research in Business and Social Sciences Vol. 3, No.1, 2014. ISSN: 2147-4478

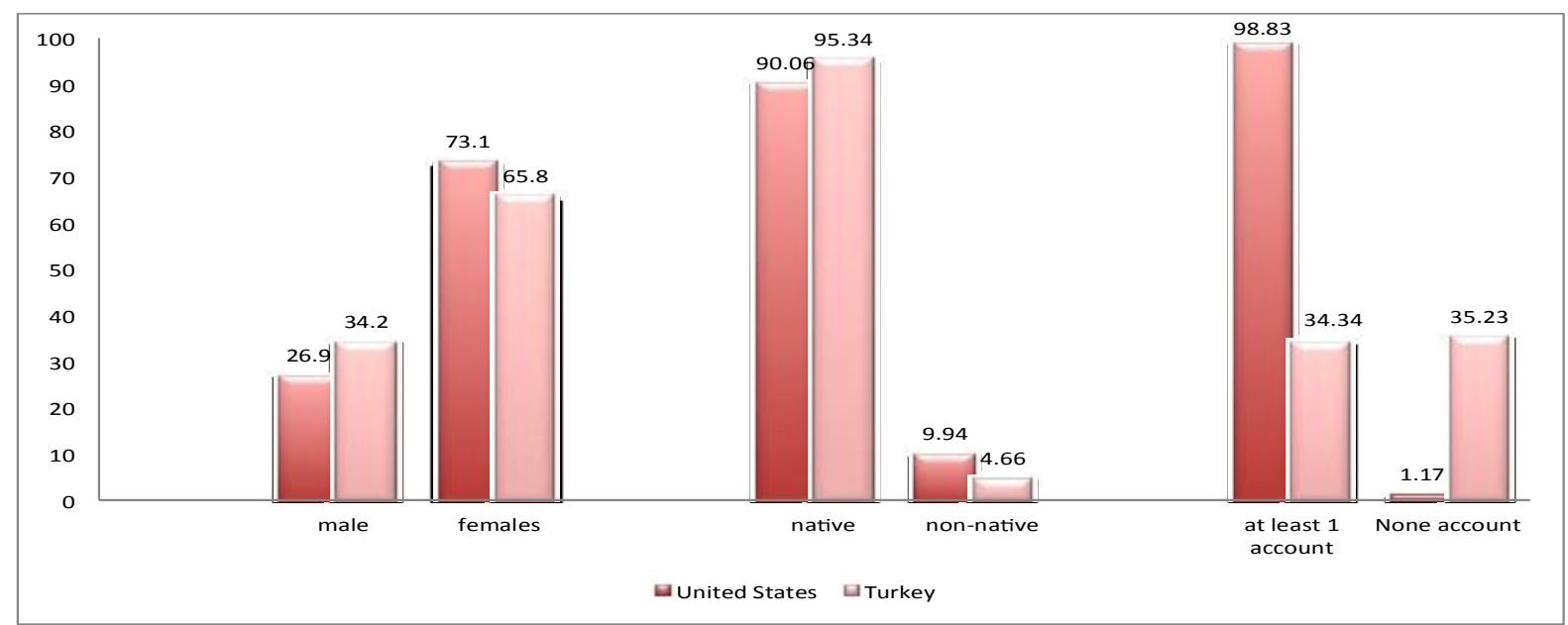

Graph 1. Independent Variable Frequency by Country

\subsubsection{Risk Tolerance Measures}

The second analyses consisted in the calculation of chi-square and frequency of the original risk tolerance categories for each measure comparing both countries (see table 2).

\subsubsection{Grable and Lytton (1999) Measure}

Specifically, from Grable and Lytton (1999), the results of chi-square test indicated that there were significant differences in each of categories on risk tolerance found in this instrument. The results of the chi-square test are as follows: $4.68 \%$ of the respondents from the United States and 19.17\% from Turkey showed high tolerance risk $\left(\chi^{2}=17.577, p<0.001\right) ; 11.70 \%$ from the Turkey group and $27.46 \%$ from the United States group exhibited above average risk tolerance $\left(\chi^{2}=14.055, p<0.001\right) ; 51.46 \%$ from the United States and $35.75 \%$ from Turkey displayed above average risk tolerance $\left(\chi^{2}=9.123, p<0.005\right) ; 23.98 \%$ from the United and $15.55 \%$ from Turkey fell in the below average category $\left(\chi^{2}=4.105, p<0.05\right)$; finally, $8.18 \%$ of the American participants and 2.07 Turkish respondents showed low tolerance $\left(\chi^{2}=7.218, p<0.05\right)($ Graph 2$)$.

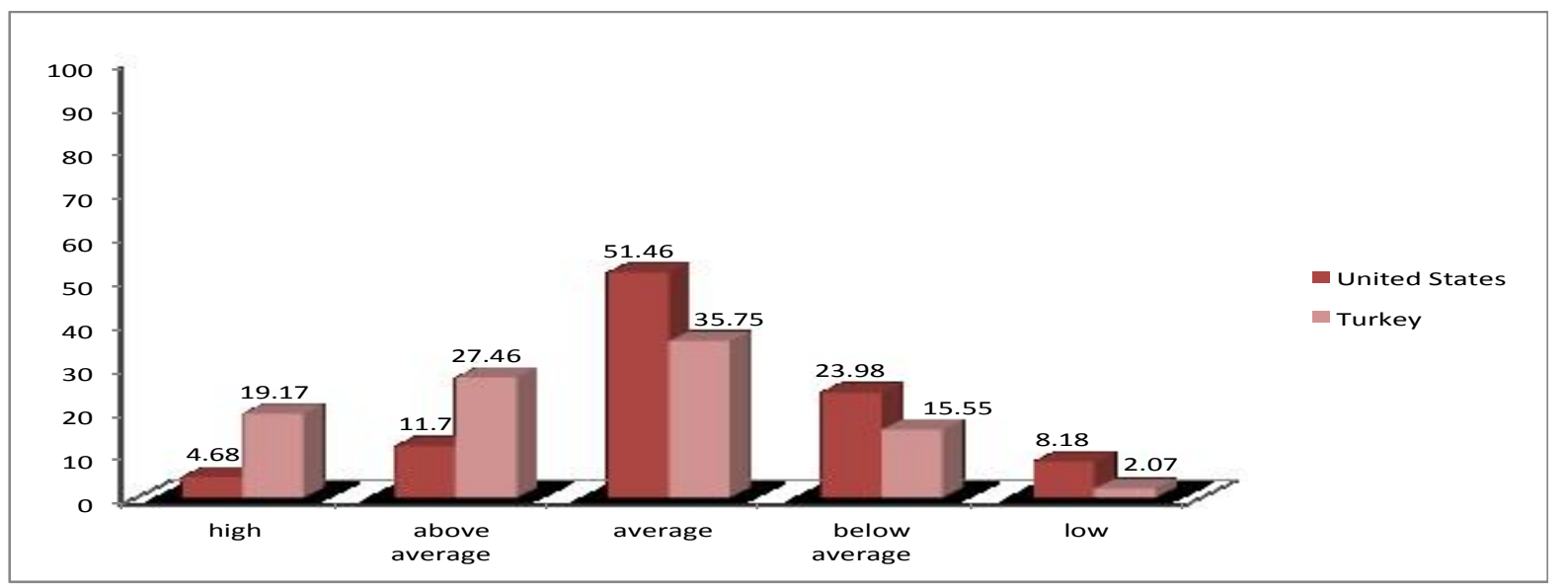

Graph 2. Grable and Lytton (1999) Response Pattern by Country 
Ruiz-Menjivar et al. /International Journal of Research in Business and Social Sciences Vol. 3, No.1, 2014. ISSN: 2147-4478

\subsubsection{Barskyet. al. (1997) Measure}

From this measure, only three categories were significantly different by country: extremely high $\left(\chi^{2}=12.633\right.$, $p<0.001)$, very high $\left(\chi^{2}=8.313, p<0.05\right)$, extremely low $\left(\chi^{2}=5.088, p<0.05\right)$. Precisely, 5.85\% of the respondents from the United States and $18.13 \%$ from Turkey feel in the extremely high category; $10.53 \%$ from the United States and $21.76 \%$ from Turkey exhibited very high-risk tolerance; and $11.69 \%$ of American respondents and 5.19\% of Turkish respondents showed extremely low risk tolerance (Graph 3).

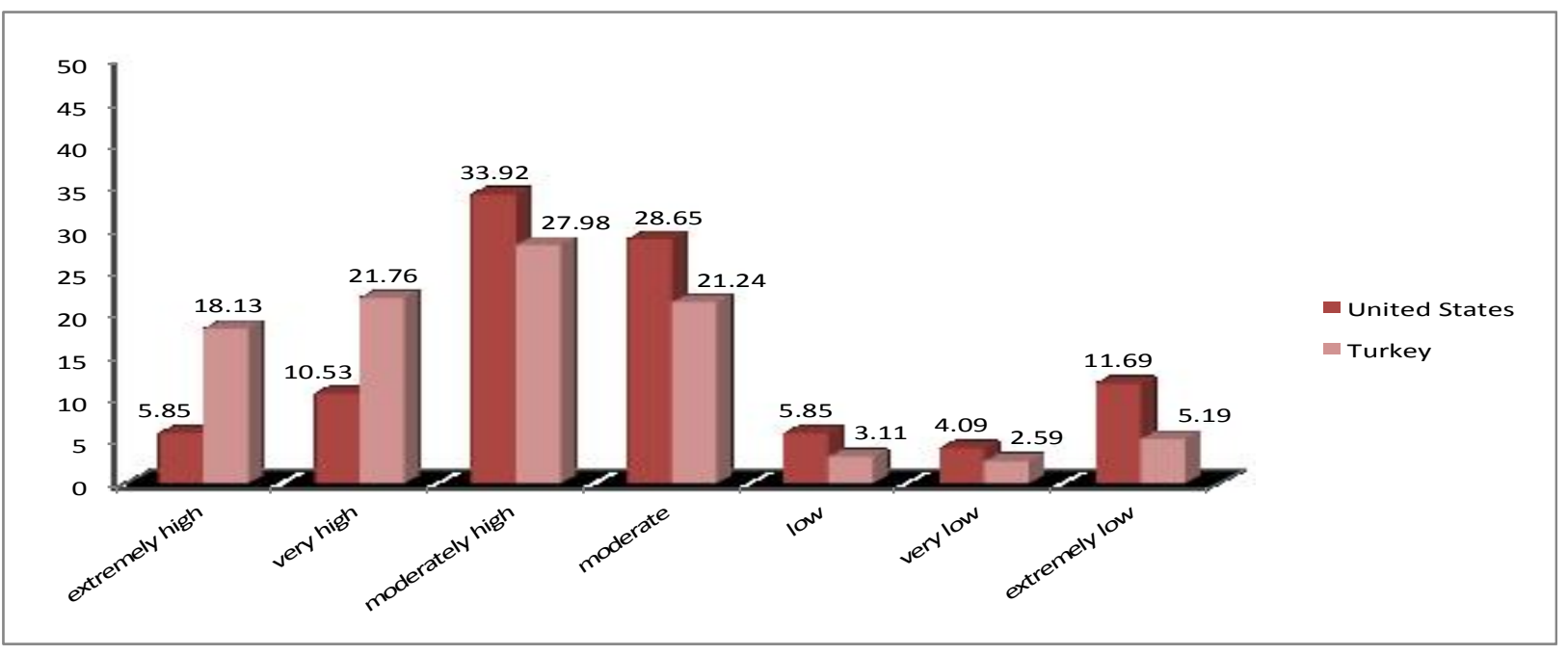

Graph 3. Barsky et al. (1997) Response Pattern by Country

\subsubsection{Survey of Consumer Finances (SCF) Question on Risk Tolerance}

From the SCF, only two categories, substantial and average, were significantly different for the United States and Turkey. The results of the $\chi^{2}$ test were as follows: $3.51 \%$ of the American sample and $10.87 \%$ displayed substantial risk tolerance $\left(\chi^{2}=7.175, p<0.05\right)$; and $66.08 \%$ of students from the American and $48.19 \%$ from the Turkish sample displayed an average level of risk tolerance (Graph 4).

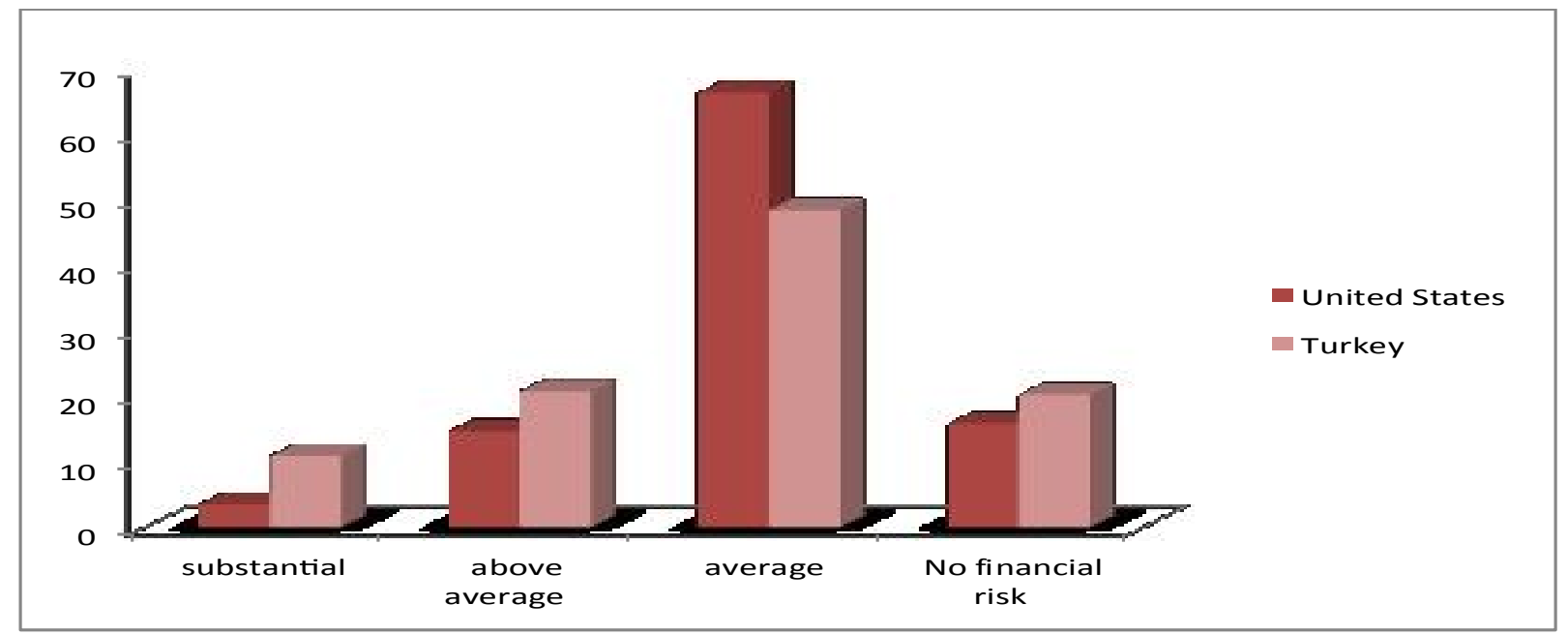

Graph 4. SCF Response Pattern by Country 
Ruiz-Menjivar et al. /International Journal of Research in Business and Social Sciences Vol. 3, No.1, 2014. ISSN: 2147-4478

Table 2. Frequency and Bivariate Analysis Results of Risk Tolerance Measures by Category

\begin{tabular}{|c|c|c|c|}
\hline & United States & Turkey & \\
\hline & Frequency $(\%)$ & Frequency $(\%)$ & Chi-Square \\
\hline \multicolumn{4}{|c|}{ Grable \& Lytton (1999) } \\
\hline High & $8(4.68)$ & $37(19.17)$ & $17.577 * *$ \\
\hline Above average & $20(11.70)$ & $53(27.46)$ & $14.0553 * *$ \\
\hline Average & $88(51.46)$ & $69(35.75)$ & $9.1238^{*}$ \\
\hline Below average & $41(23.98)$ & $30(15.55)$ & $4.1063 *$ \\
\hline Low & $14(8.18)$ & $4(2.07)$ & $7.2188^{*}$ \\
\hline \multicolumn{4}{|l|}{ Barsky et al. (1997) } \\
\hline Extremely high & $10(5.85)$ & $35(18.13)$ & $12.6336 * *$ \\
\hline Very high & $18(10.53)$ & $42(21.76)$ & $8.3139 *$ \\
\hline Moderately high & $57(33.92)$ & $54(27.98)$ & 1.5012 \\
\hline Moderate & $49(28.65)$ & $41(21.24)$ & 2.6759 \\
\hline Low & $10(5.85)$ & $6(3.11)$ & 1.6188 \\
\hline Very low & $7(4.09)$ & $5(2.59)$ & 0.6424 \\
\hline Extremely low & $20(11.69)$ & $10(5.19)$ & $5.0881 *$ \\
\hline \multicolumn{4}{|c|}{ Survey of Consumer Finances } \\
\hline Substantial & $6(3.51)$ & $21(10.87)$ & $7.1753 *$ \\
\hline Above average & $25(14.62)$ & $40(20.73)$ & 2.3042 \\
\hline Average & $113(66.08)$ & $93(48.19)$ & $11.8198 * *$ \\
\hline No financial risk & $27(15.79)$ & $39(20.21)$ & 1.1921 \\
\hline
\end{tabular}

${ }^{*} p<0.05 ; * * p<0.001$

\subsubsection{Consistency Variables}

The last part of our bivariate analysis consisted in calculating the frequency and cross tabulations for the consistency variables by country: a) consistency across all three measures, b) consistency in theoretical measures and c) consistency in non-theoretical measures (see table 3 ). The $\chi^{2}$ test indicates there were a significant difference between Turkey and the United States for the following variables: consistency in three measures $\left(\chi^{2}=14.361\right.$, $p<0.01)$ and consistency in non-theoretical measures $\left(\chi^{2}=13.419, p<0.001\right)$. Precisely, 35.67\% of the respondents from the Untied States and $18.13 \%$ from Turkey were consistent in all three measures utilized in this study. 59.65\% of the American students and $40.41 \%$ of the Turkish students exhibited consistency of response in non-theoretical measures. The bivariate result did not show a significant difference for theoretical measures. 
Ruiz-Menjivar et al. /nternational Journal of Research in Business and Social Sciences Vol. 3, No.1, 2014. ISSN: 2147-4478

Table 3. Frequency and Bivariate Analysis Results

\begin{tabular}{lllll}
\hline & \multicolumn{2}{l}{ United States } & & Turkey \\
Consistency & Frequency $(\%)$ & & Chi-Square \\
Three measures & $61(35.67)$ & $35(18.13)$ & $14.3615^{*}$ \\
Theoretical measures & $81(47.37)$ & & $74(38.34)$ & 3.021 \\
$\quad$ Non-theoretical measures & $102(59.65)$ & & $78(40.41)$ & $13.4193^{*}$ \\
$N$ of observations & $171(46.98)$ & $193(53.02)$ & \\
\hline
\end{tabular}

$* p<0.001$

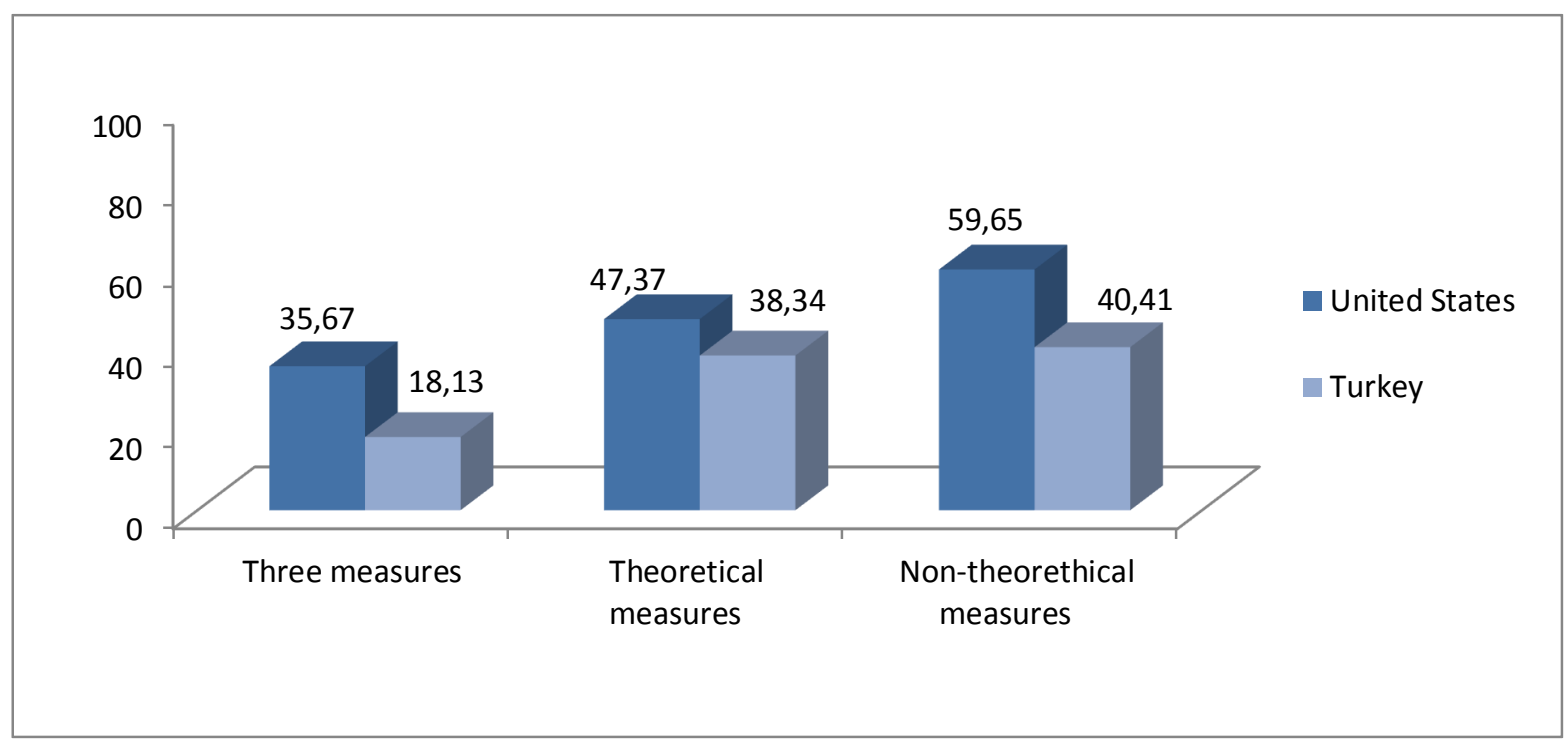

Graph 5.Consistency Variables Pattern by Country

\subsection{Cumulative Logistic Regression}

This section will present the results of the statistical regression ran for three different dependent variables: a) consistency in three measures, b) consistency in theoretical measures and c) consistency in non-theoretical measures. Table 4 summarizes the results of this statistical analysis.

The first dependent variables involved the consistency among all three measures utilized in this study: Grable and Lytton (1999), Barsky et al. (1997) and the Survey of Consumer Finances. The variable of country was statistical significant in this regression. Thus, respondents from the United States were more prone to respond consistent in all three measures than those from Turkey. The rest of the variables, native language, gender, and participation in financial services were not statistical significant.

The second dependent variable consisted in the comparison of how consistent responses were in theoretical measures; that is in Barksy et al. (1997) and the improved version of Grable and Lytton (1999) instruments. In this 
Ruiz-Menjivar et al. International Journal of Research in Business and Social Sciences Vol. 3, No.1, 2014. ISSN: $2147-4478$

model none of the variables, country, language, gender or participation in financial services was statistically significant at $p<0.05$.

Finally, "consistency in non-theoretical measures" was composed of two parts: a) the comparison of Barsky et al. (1997) instrument and the Survey of Consumer Finances (SCF), and b) the comparison of Grable and Lytton (1999) instrument and the SCF. From this regression, two variables were significant: the country of origin and native language. Therefore, American students were more likely to be consistent in non-theoretical measures than Turkish students. And if the participants were American and did speak English as native language, then, were less likely to be consistent in non-theoretical measures. 
Ruiz-Menjivar et al. /International Journal of Research in Business and Social Sciences Vol. 3, No.1, 2014.

Table 4. Estimation Results of Cumulative Logistic Regression for Consistency Models

\begin{tabular}{|c|c|c|c|c|c|c|c|c|c|}
\hline \multirow[b]{2}{*}{ Parameter } & \multicolumn{3}{|c|}{$\begin{array}{c}\text { Consistent in Three } \\
\text { Measures }\end{array}$} & \multicolumn{3}{|c|}{ Consistent in Theoretical Measures } & \multicolumn{3}{|c|}{$\begin{array}{c}\text { Consistent in Non-theoretical } \\
\text { Measures }\end{array}$} \\
\hline & Coefficient & P-value & $\begin{array}{l}\text { Odds } \\
\text { Ratio }\end{array}$ & Coefficient & P-value & $\begin{array}{l}\text { Odds } \\
\text { Ratio }\end{array}$ & Coefficient & P-value & $\begin{array}{l}\text { Odds } \\
\text { Ratio }\end{array}$ \\
\hline Intercept & -2.0575 & 0.008 & & -1.2979 & 0.0142 & & 0.5967 & 0.2727 & \\
\hline Country (United States) & $0.9404 *$ & 0.0009 & 2.561 & 0.2835 & 0.2375 & 1.328 & $0.8221 *$ & 0.0007 & 2.275 \\
\hline Language (Native speaker) & 0.3889 & 0.4296 & 1.475 & 0.4589 & 0.2882 & 1.582 & $-0.9797 *$ & 0.0344 & 0.375 \\
\hline Gender (Male) & 0.3159 & 0.2564 & 1.371 & 0.3171 & 0.1837 & 1.373 & 0.1801 & 0.4499 & 1.197 \\
\hline Participation in Financial & & & & & & & & & \\
\hline Services & -0.0594 & 0.8755 & 0.942 & 0.2653 & 0.3941 & 1.304 & -0.2673 & 0.3822 & 0.765 \\
\hline
\end{tabular}


Menjivar et al /International Journal of Research in Business and Social Sciences Vol. 3, No.1, 2014.

ISSN: $2147-4478$

\section{Conclusions and Implications}

Respondents from the Turkish sample were more likely to be categorized inconsistently across the three measures. Overall, we observed there was stronger concurrent validity for the American sample than for the Turkish group. From a cultural perspective, the consistency across measures could be the result of contextual factors for each country. Therefore, we should re-evaluate the use of American measures of financial risk tolerance internationally. Given the exploratory nature of this study, additional research should be conducted in the area of cross-cultural measurement validity of financial risk tolerance. When using instruments cross-culturally, special attention should be paid to measurement validity on the population of interest. As noted, none of the variables was significant in the theoretical model. Although, theories could grasp different dimension of a construct; ultimately, the consistency should be same. Thus, future research should also focus on the different dimensions as those proposed by various existing instruments (Grable \& Lytton, (1999): investment risk, risk comfort and experience, and speculative risk; Survey of Consumer Finances: investment; Barsky et al., (1997): income loss).

In addition, further research should place emphasis on financial risk tolerance predictors. For instance, the studies should take into consideration predicting variables such planning horizon along with a more extensive list of demographic variables. It would be pivotal to include among those demographic variable, life cycle variables (age, presence of offspring, etc.). Future studies might be able to investigate more on whether inconsistencies in risk tolerance measures proxied by age or other life cycle variables are consistent with the results of this exploratory study. In general, conducting research with a more diverse sample made of various respondents from different life cycle stages will provide the opportunity to draw more meaningful inferences.

Finally, this study brings important implications not only for researchers but also for financial planners and professional in the financial field. In the context of Turkey with a relative emerging market of financial services, special attention should be granted to the accurate measurement of financial behavioral attitudes, in this case risk tolerance. It is pivotal the consideration of such assessment and the determinants of risk tolerance when delivering services and rendering services to clients. In addition, the major conclusion for financial planners in the United States is that when working domestically with international clients, it is crucial consider particular contextual factors to the country of origin when measuring risk attitude behaviors.

\section{References}

Adcock, R., Collier, D. (2001). Measurement validity: a shared standard for qualitative and quantitative research. American Political Science Review, 95(3), 529-546.

Barsky, R. B., Juster, F. T., Kimball, M. S. \& Shapiro, M. D. (1997). Preference parameters and behavioral heterogeneity: An experimental approach in the Health and Retirement Study. The Quarterly Journal of Economics, $112(2), 537-579$.

Blanco, A., Gutter, M., Ruiz-Menjivar, J., Spangler, T. \& Wynn, K. (2012). A comparison of three measures of risk tolerance. Consumer Interest Annual, 58. 
Menjivar et al /International Journal of Research in Business and Social Sciences Vol. 3, No.1, 2014.

ISSN: $2147-4478$

Copur, Z., Gutter, M. S., Erkal, S. (2010). Exploring saving behavior of Turkish families in Ankara/Turkey. International Journal of Economics and Finance Studies, 2(2), 105-112.

Fan, J. X., Xiao, J. J. (2006). Cross-cultural differences in risk tolerance: a comparison between Chinese and Americans. Journal of Personal Finance, 5(3), 54-75.

van Belle, G. (2011). Statistical Rules of Thumb. (2nd ed.). John Wiley and Sons, New York. ISBN 1118210360 , 9781118210369 , p. $45-46$.

Grable, J. E., \& Lytton, R. H. (1999). Financial risk tolerance revisited: the development of risk assessment instrument. Financial Services Review, 8(3), 163-181.

Grable, J. E., \& Lytton, R. H. (2001). Assessing the concurrent validity of the SCF risk tolerance question. Financial Counseling and Planning, 12(2), 43-53.

Grable, J. E., \& Schumm, W. (2007). An estimation of the reliability of the Survey of Consumer Finances risk tolerance question. TCAI Working Paper: Universityof Arizona, 1-28.

Hanna, S. D., Gutter, M. S., \& Fan, J. X. (2001). A measure of risk tolerance based on economic theory. Financial Counseling and Planning, 12(2), 53-60. 